\title{
OPEN A role for cortical dopamine in the paradoxical calming effects of psychostimulants
}

\author{
Sharonda S. Harris, Sara M. Green, Mayank Kumar \& Nikhil M. Urs ${ }^{\bowtie}$
}

Psychostimulants have a paradoxical calming effect in the treatment of attention deficit hyperactivity disorder (ADHD), but their mechanism of action is unclear. Studies using dopamine (DA) transporter (DAT) knockout (KO) mice have suggested that the paradoxical calming effect of psychostimulants might occur through actions on serotonin $(5-\mathrm{HT})$ neurotransmission. However, newer non-stimulant drugs, such as atomoxetine and guanfacine, suggest that targeting the norepinephrine (NE) system in the prefrontal cortex (PFC) might explain this paradoxical calming effect. Thus, we sought to clarify the mechanism of this paradoxical action of psychostimulants. Our ex vivo efflux experiments reveal that the NE transporter (NET) blocker desipramine elevates both norepinephrine (NE) and dopamine (DA), but not 5-HT levels, in PFC tissue slices from wild-type (WT) and DAT-KO, but not NET-KO mice. However, the 5-HT transporter (SERT) inhibitor fluoxetine elevates only 5-HT in all three genotypes. Systemic administration of desipramine or fluoxetine inhibits hyperactivity in DAT-KO mice, whereas local PFC infusion of desipramine alone produced this same effect. In contrast, pharmacological NE depletion and DA elevation using nepicastat also inhibits hyperactivity in DAT-KO mice. Together, these data suggest elevation of PFC DA and not NE or 5-HT, as a convergent mechanism for the paradoxical effects of psychostimulants observed in ADHD therapy.

Attention deficit hyperactivity disorder (ADHD) affects at least 5-10\% of children, with increasing diagnoses every year. The primary line of treatment for ADHD are the psychostimulant class of drugs, including amphetamine (Aderall) and methylphenidate (Ritalin). Several theories have been postulated on the paradoxical calming effect of psychostimulants in ADHD patients. However, after decades of research, their exact molecular and anatomical mechanism of action is not clear. Studies on the role of different monoamine transporters in the actions of psychostimulants have been inconclusive. Using the hyperactive dopamine (DA) transporter (DAT) knockout (DAT-KO) mice, studies have shown that administration of the 5-HT transporter (SERT) inhibitor fluoxetine or the 5-HT precursor 5-HTP, reduces hyperactivity in these mice ${ }^{1,2}$. These data suggest a serotonergic mechanism of action mediating this behavioral effect. However, microdialysis studies using fluoxetine, propose a role for cortical norepinephrine (NE) and $\mathrm{DA}^{3,4}$. Additionally, newer non-stimulant forms of ADHD medications (atomoxetine, guanfacine) alter NE transmission, thus providing evidence for a role for the NE transporter (NET) in this paradoxical calming effect. Interestingly, NET knockout (NET-KO) mice have reduced locomotor activity and lower striatal DA release ${ }^{5}$, again suggesting a crucial role for NET in this calming effect. However, NET inhibition not only elevates NE levels, but also DA levels in the $\mathrm{PFC}^{4-6}$. Consequently, it is still unclear whether PFC NE, DA or 5-HT are necessary for the paradoxical effects of psychostimulants.

We hypothesize that PFC DA is the common mechanism that drives this paradoxical effect. Previous microdialysis studies established an inverse relationship between DA levels in the PFC and striatal DA levels, and locomotor activity ${ }^{7,8}$. DA depletion by pharmacological lesioning in the PFC has been shown to increase subcortical DA levels and amphetamine-induced locomotor activity ${ }^{7,9,10}$. Additionally, we have previously shown that DA D2 receptor deletion in the PFC increases PCP-induced hyperactivity (Urs et al., 2016).

The present study investigated the effects of pharmacological agents that increase PFC DA levels on locomotor activity. The current study provides mechanistic insight into the regulation of PFC monoamines and their role in the paradoxical effects of psychostimulants. 

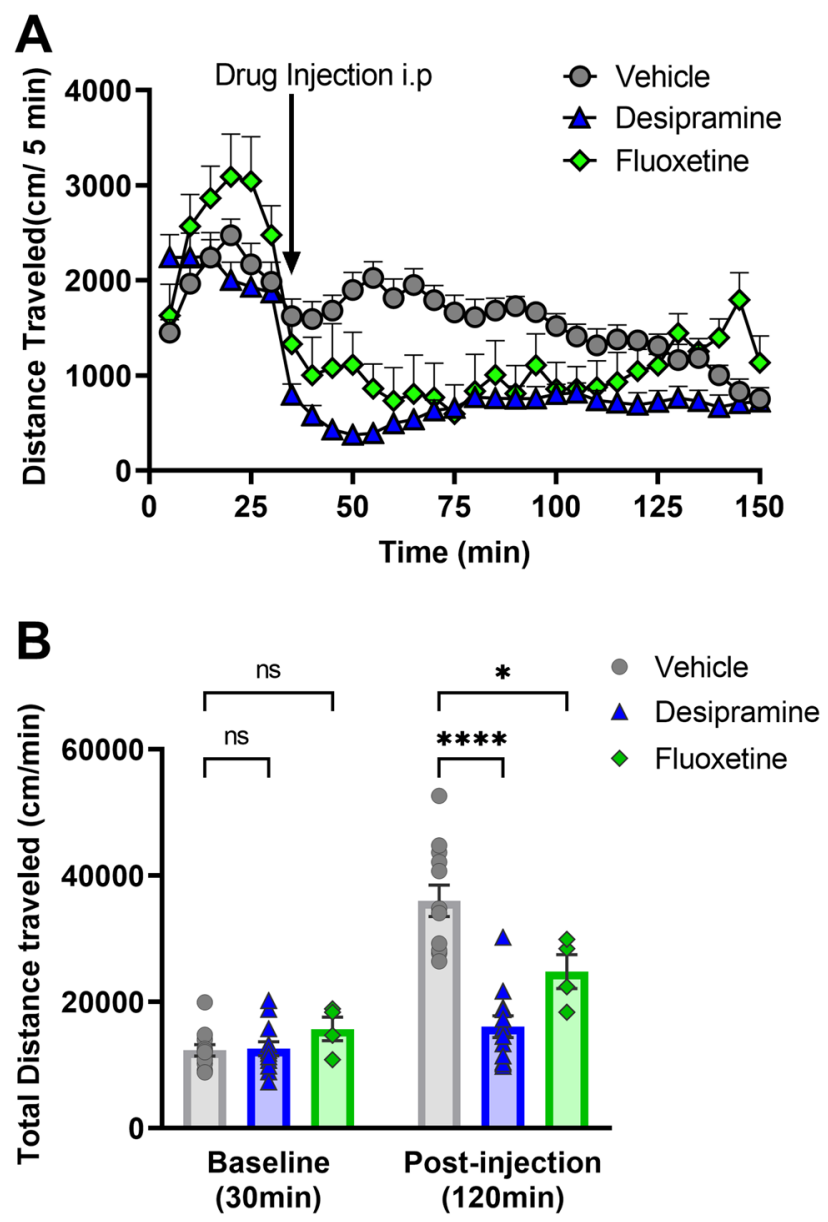

Figure 1. Effect of monoamine transporter drugs on DAT-KO hyperactivity. Hyperactive DAT-KO mice were systemically injected with vehicle (saline) or the transporter blockers desipramine (NET) (i.p.) or fluoxetine (SERT) (s.c). (A) Locomotor activity ( $\mathrm{cm} / 5 \mathrm{~min}$ ) was recorded for $120 \mathrm{~min}$, preceded by a $30 \mathrm{~min}$ baseline recording. (B) Total distance traveled for baseline $(\mathrm{cm} / 30 \mathrm{~min})$ and post-injections sessions $(\mathrm{cm} / 120 \mathrm{~min})$ were calculated. $\mathrm{N}=6-12$ mice per group. $\mathrm{F}(2,26)=23.44,{ }^{\star} \mathrm{P}<0.05,{ }^{* \star * \star} \mathrm{P}<0.0001$ using two-way ANOVA, compared to Vehicle-treated controls, ns- not significant.

\section{Results}

Previous reports have shown that NET-KO mice have reduced locomotor activity ${ }^{5}$, whereas hyperactivity in DATKO is reduced by SERT inhibition ${ }^{1}$. We sought to test the effects of NET or SERT inhibition on locomotor activity in DAT-KO mice. Systemic administration of the NET inhibitor, desipramine ( $25 \mathrm{mg} / \mathrm{kg}$, i.p. $)$, or the SERT inhibitor, fluoxetine $(20 \mathrm{mg} / \mathrm{kg}$, s.c.), significantly decreased hyperactivity in DAT-KO mice, compared to vehicle (saline) injected controls (Fig. 1). Our findings are in contrast to the original study ${ }^{1}$, which shows that NET inhibition using nisoxetine does not affect hyperactivity in the DAT-KO mice.

The prefrontal cortex (PFC) is thought to be the site of psychostimulant action and other therapeutics used to treat $\mathrm{ADHD}^{11,12}$ given that they improve motivational and cognitive functions. We asked the question if desipramine and fluoxetine alter monoamine levels in the PFC. To test this, we used a previously established ex vivo efflux assay ${ }^{13,14}$ that allows measurement of monoamines released from brain tissue slices submerged in oxygenated buffer. Monoamine release from the slices is induced by potassium chloride $(\mathrm{KCl})$ application and measured by HPLC. KCl-mediated increases in monoamine levels can be further enhanced by application of specific monoamine transporter blockers or by drugs such as amphetamine (Amph) (see "Methods" section for details), which alter presynaptic reuptake of monoamines. We first tested Amph-induced efflux in PFC tissue slices from WT, DAT-KO, and NET-KO mice. Amph significantly elevated DA levels in DAT-KO mice, but not WT or NET-KO mice (Fig. 2A). Amph elevated NE and 5-HT to similar levels in PFC slices from WT compared to DAT-KO or NET-KO mice. Amph-induced monoamine release was normalized to baseline KCl-induced monoamine release (Fig. 2B), which did not show significant changes between genotypes. All raw values of monoamine levels in PFC tissue for Fig. 2 are shown in supplemental data Table 1.

However, there was a trend towards an Amph-induced reduction in NE levels in the NET-KO mice. Amph binds to all monoamine transporters non-specifically and elevates monoamine levels by inducing reverse transport. We next tested the effects of specific transporter blockers, desipramine, GBR12909 and fluoxetine, that 


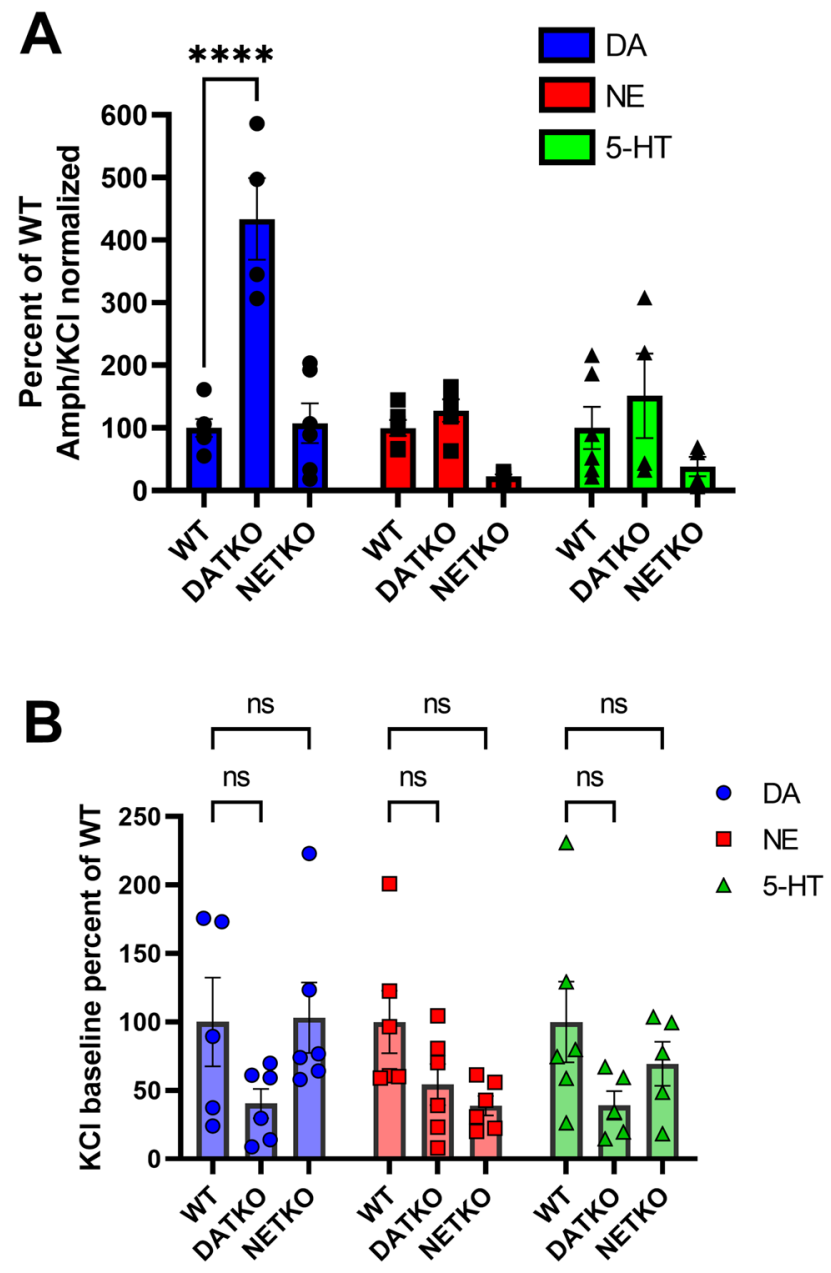

Figure 2. Effect of Amphetamine on monoamine efflux in PFC tissue. (A) PFC tissue slices from WT, DAT-KO and NET-KO mice were treated with amphetamine (AMPH, 10uM), and monoamines released into the KH incubation buffer were analyzed by HPLC. For each monoamine, Amph-induced release was normalized to $\mathrm{KCl}$-induced release (shown in B) for each respective genotype and then normalized to WT levels. F (2, $42)=7.325$ for genotype comparisons. ${ }^{* * *} \mathrm{P}<0.0001$ using two-way ANOVA, compared to WT mice. $\mathrm{n}=2$ experiments with 3 mice in each experiment. (B) PFC tissue slices from WT, DAT-KO and NET-KO mice were treated with $40 \mathrm{mM} \mathrm{KCl}$, and monoamines released into the $\mathrm{KH}$ incubation buffer were analyzed by HPLC. For each monoamine, $\mathrm{KCl}$-induced release was normalized to WT levels. $n s$ Not significant using two-way ANOVA, compared to WT mice. $\mathrm{n}=3-4$ experiments with 4 mice in each experiment.

inhibit NET, DAT and SERT, respectively. In WT mice, NET inhibition with desipramine (10 uM) increased $\mathrm{KCl}$-stimulated NE and DA but not 5-HT compared to $\mathrm{KCl}$ alone (Fig. 3Ai, DA; Aii NE). As expected, SERT inhibition with fluoxetine (10 uM) increased KCl-stimulated 5-HT in WT mice, but did not alter NE or DA levels (Fig. 3Aiii, 5-HT). Our findings are in contrast to previous microdialysis studies showing that fluoxetine elevates NE and DA in the PFC ${ }^{3,4}$. GBR12909 had no effect on any of the monoamine levels in PFC tissue slices, consistent with evidence that in the PFC DAT expression is very low compared to the striatum, and reuptake of DA is primarily mediated by NET ${ }^{6,15,16}$. In DAT-KO mice, NET inhibition with desipramine led to a significant increase in $\mathrm{KCl}$-stimulated $\mathrm{NE}$ and $\mathrm{DA}$, but not 5-HT levels compared to $\mathrm{KCl}$ treatment alone (Fig. 3Bi, $\mathrm{DA}$; 3Bii, NE). The increase in DA levels in DAT-KO mice was much higher than that of WT mice $(\mathrm{p}<0.05$ vs $\mathrm{p}<0.0001)$. Similar to WT mice, SERT inhibition in DAT-KO mice using fluoxetine led to a significant increase in KCl-stimulated 5-HT levels, but not NE or DA levels, compared to KCl treatment alone (Fig. 3Biii, 5-HT). Neither NET nor DAT inhibition with desipramine or GBR12909, respectively, had any effect on KCl-stimulated NE, DA, or 5-HT levels in NET-KO mice (Fig. 3Ci-iii). Conversely, SERT inhibition with fluoxetine increased KCl-stimulated 5-HT, but not NE or DA (Fig. 3Ci-iii, 5-HT).

Since our results showed that systemic NET inhibition reduces hyperactivity in DAT-KO mice and that NET inhibitors elevate both NE and DA levels in the PFC of DAT-KO mice, we next tested the effect of PFC NET inhibition on locomotor hyperactivity of DAT-KO mice. Bilateral PFC infusion of desipramine $(4 \mu \mathrm{g} / 0.5 \mu \mathrm{l} /$ side) significantly reduced hyperactivity in DAT-KO mice (Fig. 4A,B). Consistent with our efflux data, bilateral infusion of fluoxetine did not significantly affect hyperactivity in DAT-KO mice (Fig. 4A,B). However, bilateral infusion of Amph (100uM/0.5ul/side) significantly reduced hyperactivity in DAT-KO mice (Fig. 4B). 
Ai WT

Bi

DATKO

Ci

NETKO
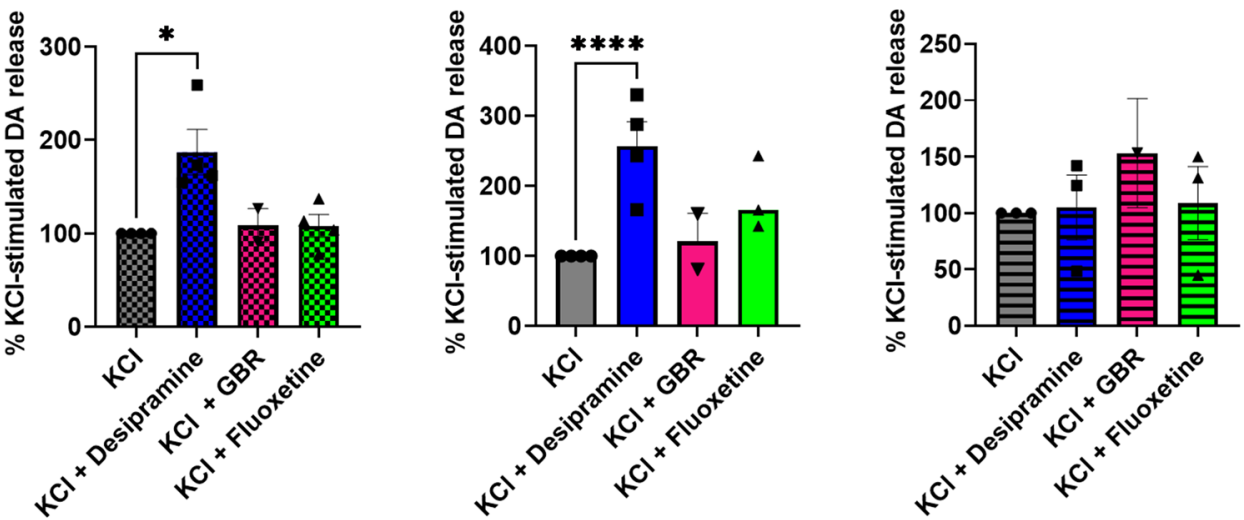

Aii

Bii

\section{Cii}
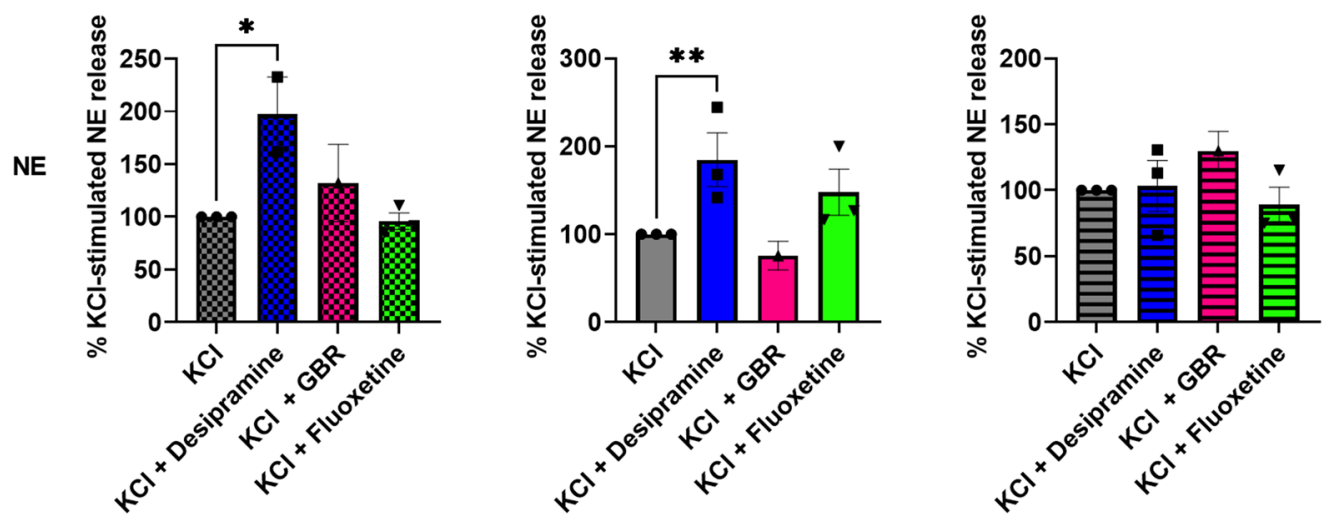

\section{Aiii}

Biii

\section{Ciii}
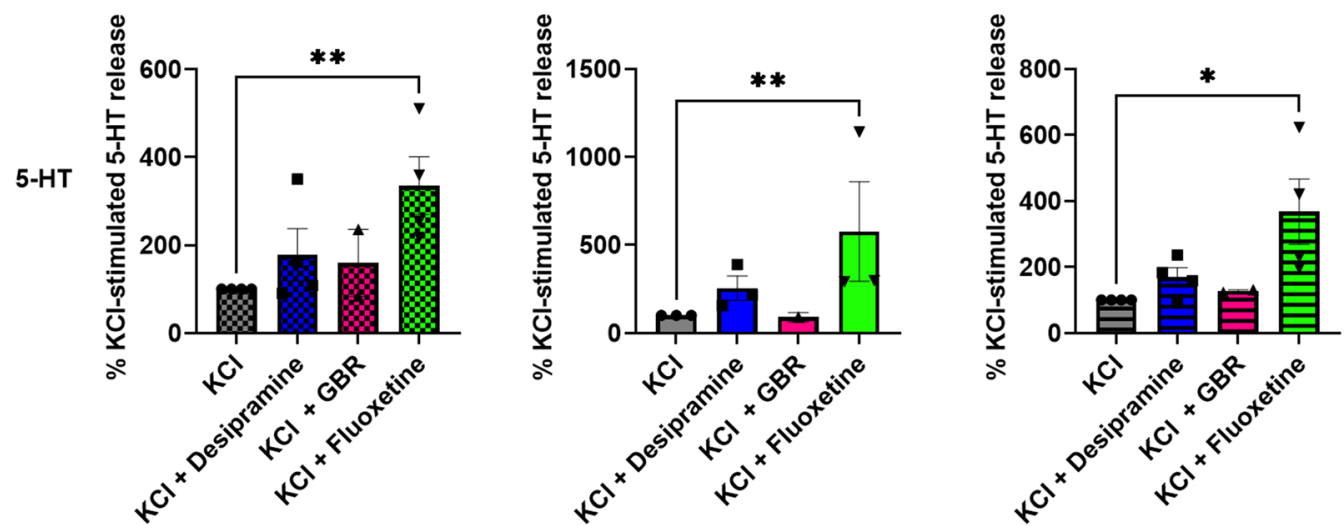

Figure 3. Effect of monoamine transporter blockers on monoamine efflux in PFC tissue. PFC tissue slices from WT, DAT-KO and NET-KO mice were treated with $\mathrm{KCl}$ alone $(40 \mathrm{mM})$ or $\mathrm{KCl}+10 \mu \mathrm{M}$ desipramine, GBR12909 (GBR) or fluoxetine. Monoamines released into the KH incubation buffer were analyzed by HPLC. $\mathrm{F}(3,21)=3.712$ WT NE, F $(3,34)=3.284$ WT DA, F $(3,35)=5.957$ WT 5-HT, F $(3,32)=10.85$ DAT-KO DA, F $(3,24)=5.003$ DAT-KO NE, F $(3,20)=8.410$ DAT-KO 5-HT, F $(3,24)=0.5012$ NET-KO DA, F $(3$, $24)=0.4536$ NET-KO NE, $\mathrm{F}(3,35)=3.578$ NET-KO 5-HT, for drug treatment comparisons. ${ }^{*} \mathrm{P}<0.05,{ }^{*} \mathrm{P}<0.01$, ${ }^{* * * \star} \mathrm{P}<0.0001$ using two-way ANOVA, compared to KCl-treated controls. $\mathrm{n}=3-4$ experiments with 4 mice in each experiment. 

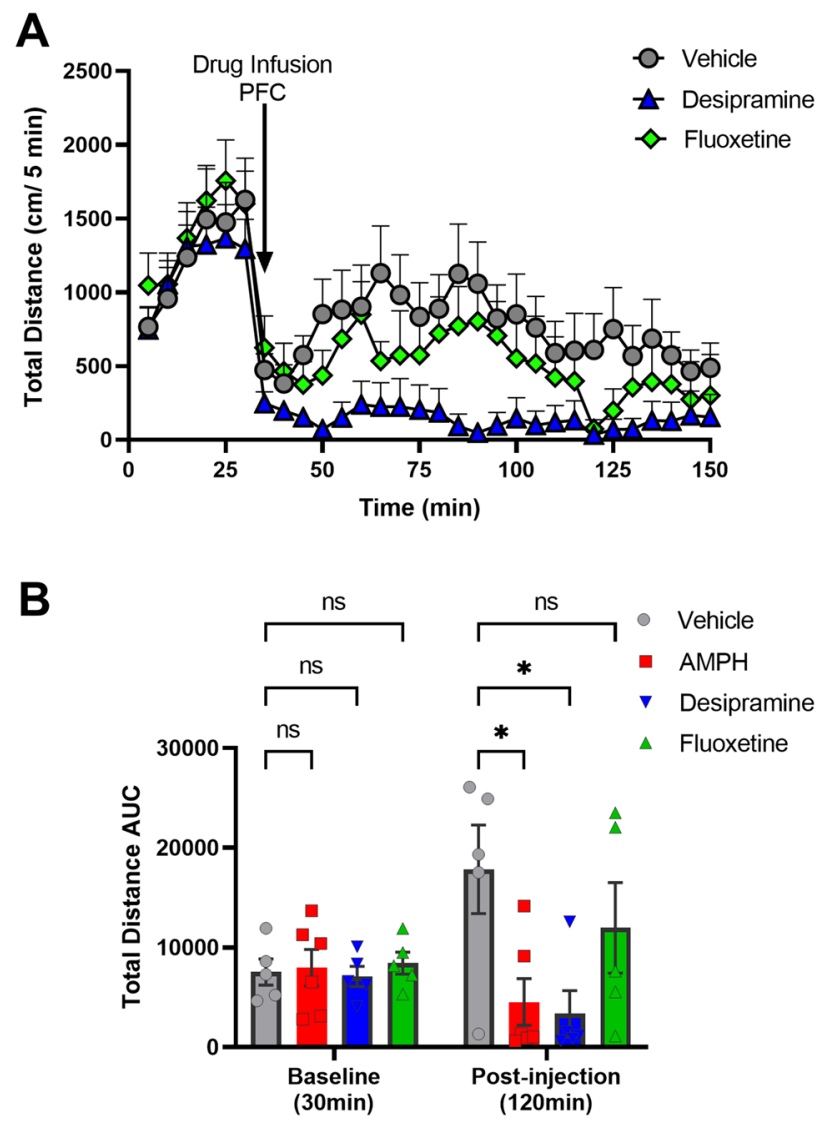

Figure 4. Effect of PFC infusion of monoamine transporter drugs on DAT-KO hyperactivity. (A) Hyperactive DATKO mice were infused (drug infusion PFC) with vehicle (aCSF) or $4 \mathrm{ug} / 0.5 \mathrm{ul}$ of desipramine or fluoxetine (dissolved in aCSF) in the PFC, after a $30 \mathrm{~min}$ baseline, and locomotor activity $(\mathrm{cm} / 5 \mathrm{~min}$ ) was recorded for 120 min post-infusion. (B) Baseline $(\mathrm{cm} / 30 \mathrm{~min})$ and post-infusion $(\mathrm{cm} / 120 \mathrm{~min})$ total distance traveled was measured upon local infusion of desipramine, amphetamine (AMPH) or fluoxetine. $n=6-8$ mice per group. Pairwise comparisons using Two-way ANOVA, F $(4,52)=2.973{ }^{\star} \mathrm{p}<0.05$, ns not significant.

Since NET inhibitors elevate NE and DA levels in the PFC of DAT-KO and reduce hyperactivity, we next sought to test the effect of NE depletion in DAT-KO mice. We tested this using the DA beta hydroxylase (DBH) inhibitor nepicastat, which depletes NE levels in the brain ${ }^{17,18}$. DBH metabolizes DA to NE, therefore, nepicastat not only depletes NE levels, but also enhances DA levels in the $\mathrm{PFC}^{19}$. Systemic administration $(40 \mathrm{mg} / \mathrm{kg}$, i.p.) (Fig. 5A,B) or bilateral PFC infusion $(4 \mu \mathrm{g} / 0.5 \mu \mathrm{l} /$ side) (Fig. 5C,D) of nepicastat reduced hyperactivity in DATKO mice. HPLC analysis of PFC tissue from DAT-KO mice systemically injected with nepicastat showed reduced tissue NE levels and elevated tissue DA levels without altering 5-HT levels (Fig. 5E).

\section{Discussion}

In this study, we apply an integrated approach, using ex vivo efflux techniques, monoamine transporter genetic knockouts, and behavior, to understand the molecular and anatomical mechanisms that regulate the phenomenon of paradoxical calming effects of psychostimulants in ADHD therapy. We showed that the NET inhibitor desipramine, but not the SERT inhibitor fluoxetine, elevates NE and DA levels from PFC tissue slices. Importantly, local PFC infusion of the NET blocker desipramine or DBH inhibitor nepicastat inhibits hyperactivity in DAT-KO mice. These data suggest that elevated PFC DA is a common mechanism that drives the paradoxical calming effect of psychostimulants.

We observe that systemic administration of desipramine and fluoxetine reduces hyperactivity in DAT-KO mice, which are consistent with previous findings. However, our findings are in contrast with a previous study that failed to show a reduction in hyperactivity in DAT-KO mice following treatment with the NET inhibitor nisoxetine ${ }^{1}$. The dose of nisoxetine used in the previous study was $10 \mathrm{mg} / \mathrm{kg}$, whereas other studies found that higher doses of nisoxetine did produce behavioral effects in DAT-KO mice ${ }^{20}$. The present study, as well as previous studies, thus suggest a role for NET in the paradoxical calming effects in DAT-KO mice. Our findings are consistent with a role for NET in regulating locomotor activity ${ }^{5}$. Thus, both NET and SERT may play a role in the paradoxical calming phenomenon of psychostimulants. However, the exact anatomical and molecular mechanisms of this phenomenon are not clear. Studies have suggested that the site of action of these psychostimulants is in the PFC, using very low doses of psychostimulants. Low dose administration of psychostimulants is thought to preferentially affect monoamine physiology through PFC, and not striatal, monoamine transporters ${ }^{11}$. 
A

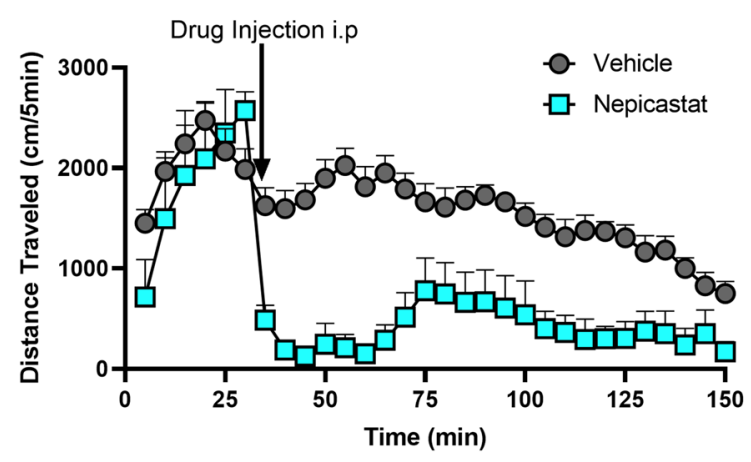

C

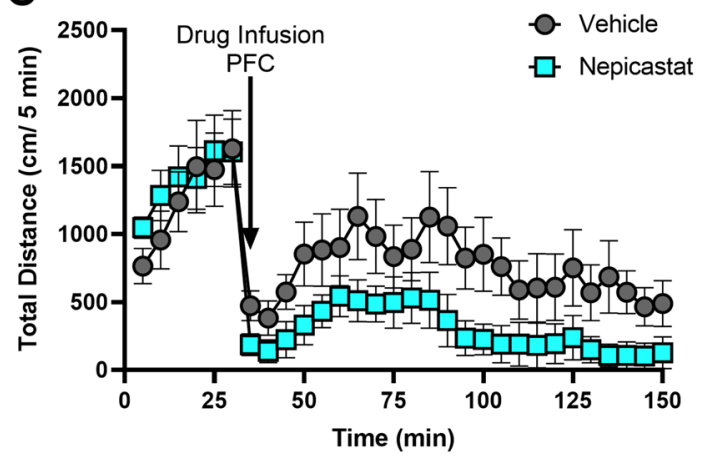

B

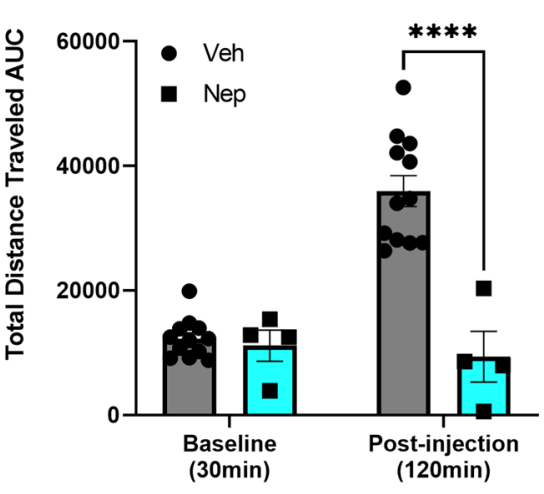

D

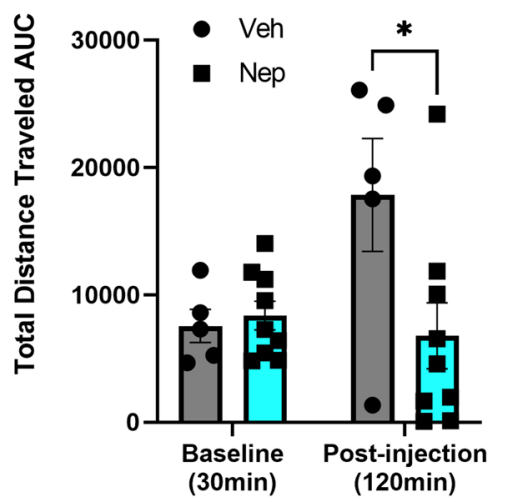

$\mathbf{E}$

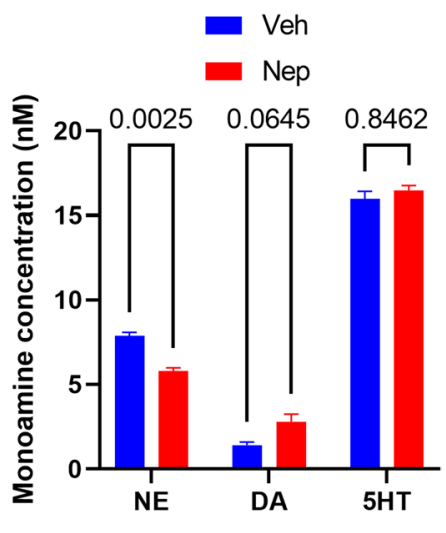

Figure 5. Effect of systemic or local PFC nepicastat administration on DAT-KO hyperactivity. (A) Locomotor activity $(\mathrm{cm} / 5 \mathrm{~min}$ ) of hyperactive DAT-KO mice was recorded for a $30 \mathrm{~min}$ baseline measurement followed by systemic injection with nepicastat or vehicle, and an additional $120 \mathrm{~min}$ of post-injection activity was recorded. (B) Total distance traveled $(\mathrm{cm} / 150 \mathrm{~min})$ was calculated. $\mathrm{n}=6-12$ mice per group. Pairwise comparisons using Two Way ANOVA, ${ }^{* * *} \mathrm{p}<0.0001$. DAT-KO mice were infused with vehicle or $4 \mathrm{ug} / 0.5 \mathrm{ul}$ of nepicastat in the PFC. (C) Locomotor activity $(\mathrm{cm} / 5 \mathrm{~min})$ was recorded for a $30 \mathrm{~min}$ baseline and an additional post-infusion recording of $120 \mathrm{~min}$. (D) Total distance traveled (AUC) was calculated for baseline $(\mathrm{cm} / 30 \mathrm{~min}$ ) and postinfusion (cm/120 min). Pairwise comparisons using Two-way ANOVA, F $(4,52)=2.973,{ }^{*} \mathrm{p}<0.05$. (E) DAT-KO PFC tissue was analyzed upon nepicastat (Nep) i.p. injection for NE, DA or 5-HT levels by HPLC. P-values calculated using Two-way ANOVA, F $(2,18)=1016$, Nep compared to vehicle (veh) treated, $\mathrm{n}=4$.

Consistent with these studies, we observed that NE and DA levels are elevated in DAT-KO mice in the presence of the NET inhibitor desipramine. This effect is mediated by NET, since NET-KO mice did not show elevated NE and DA levels. It is possible that these effects could be due to compensatory changes due to lifelong deletion of DAT. We found no alterations in PFC tissue monoamine levels in DAT-KO mice, but significantly lower PFC NE tissue levels in NET-KO mice (Fig. S1), as shown by HPLC. These results suggest that the increase in stimulated monoamine release in DAT-KO mice are not due to homeostatic changes in the PFC. Our notion is consistent with previous studies showing that monoamine transporter expression is unaffected in DAT-KO mice, although alterations in striatal D2 receptors are observed ${ }^{21}$. Unlike desipramine, our efflux studies show that fluoxetine elevates only 5-HT levels and not NE or DA. This is in contrast to previous microdialysis studies showing that fluoxetine increases PFC NE and $\mathrm{DA}^{3,4}$. This discrepancy can be explained by the fact that we used brain tissue slices, in which the long-range connectivity of PFC afferents from midbrain or hindbrain is disrupted, whereas in microdialysis studies, this connectivity is maintained. Additionally, in our PFC infusion experiments, desipramine, but not fluoxetine, reduced DAT-KO hyperactivity. This suggests that the site of action for fluoxetine is presumably outside of the PFC, since systemic administration of fluoxetine does reduce DAT-KO hyperactivity. Recent anatomical mapping studies have suggested that serotonergic raphe nuclei send dense projections to VTA DA neurons and locus coeruleus (LC) NE neurons that project to the medial $\mathrm{PFC}^{22-24}$. It is likely that fluoxetine's action on raphe terminals at mesocortical DA or LC neurons activates these neurons and their cortical projections to elevate PFC DA and NE levels, respectively. Another study suggesting a possible serotonergic mechanism administered the 5-HT precursor 5-HTP, and also showed a reduction in DAT-KO hyperactivity ${ }^{1}$. However, it is possible that excess systemic 5-HTP levels overload the decarboxylase enzyme that is also present in other monoaminergic neurons, such as DA neurons. Such an overload could lead to depletion of striatal dopamine, similar to administration of the tyrosine hydroxylase inhibitor alpha-methyl-p-tyrosine, which has been shown to inhibit DAT-KO hyperactivity ${ }^{25}$. Overall, two distinct possible mechanisms, i.e. desipramine in the PFC and fluoxetine in the mid/hind-brain, may regulate DA and NE levels in the PFC. However, PFC infusion of the 
DBH inhibitor nepicastat, which depletes NE while elevating DA, also inhibits hyperactivity in DAT-KO mice. Together, these data suggest PFC DA, and not NE or 5-HT, serves as a convergent signal for distinct mechanisms of NET or SERT regulation of hyperactivity in DAT-KO mice. This hypothesis is consistent with previous data suggesting an inverse role of cortical DA and striatal DA in regulating locomotor activity ${ }^{7,8}$.

Thus, our data provide a mechanistic insight into possible mechanisms of the paradoxical calming effects of psychostimulants and highlight a predominant role for cortical DA in this phenomenon. Our previous studies have identified a possible cortico-striatal-midbrain circuit involved in cortical DA control of striatal DA function and behaviors ${ }^{26}$. Future studies elucidating the circuit mechanisms regulated by this cortical DA-dependent phenomenon will provide a possible platform for studying the regulation of striatal DA dysfunction, which is a pathological feature of multiple neurological and psychiatric disorders.

\section{Methods}

Animals and drugs. All mouse studies were conducted in accordance with the NIH guidelines for animal care and use and with an approved animal protocol from the University of Florida Animal Care and Use Committee. Studies were conducted in compliance with ARRIVE guidelines. The DAT-KO ${ }^{2}$ and NET-KO ${ }^{5}$ mice were obtained from Dr. Marc Caron (Duke University). The knockout mice and littermate controls were backcrossed on to a C57BL6/J background for at least 10 generations and are maintained on this background. 2-5 month old mice of both sexes were used for all studies. Amphetamine (Amph, Sigma), desipramine (Sigma), fluoxetine (Sigma), and GBR12909 (R\&D systems) were dissolved in saline (behavior) or efflux buffer (efflux assays). Nepicastat (Medkoo, Morrisville, NC) was dissolved in 1\% DMSO and 10\% hydroxypropyl-cyclodextrin (Sigma) and brought up to volume with saline. Appropriate solvent solutions were used as vehicle controls. For systemic injections, all drugs were injected at a volume of $10 \mathrm{ml} / \mathrm{kg}$ animal weight.

Locomotor activity. Locomotor activity was measured in an Accuscan activity monitor (Accuscan Instruments, Columbus, $\mathrm{OH}$ ) as described previously ${ }^{27}$. Briefly, locomotor activity was measured at 5 min intervals, and the total distance traveled in $5 \mathrm{~min}$ increments for a total of $150 \mathrm{~min}$ or as mentioned in figures were analyzed. Mice were acclimatized to the activity monitoring chambers for $30 \mathrm{~min}$ prior to any drug treatments. Drugs were administered after the acclimatization period and locomotor activity was recorded for an additional $120 \mathrm{~min}$.

Ex vivo monoamine release (efflux) assay. Wild-type (WT), DAT-KO and NET-KO mice were sacrificed and brains were quickly removed and immersed in ice-cold Krebs-Henseleit $(\mathrm{KH})$ buffer in the presence of $400 \mu \mathrm{M}$ ascorbic acid. The composition of $\mathrm{KH}$ buffer in $\mathrm{mM}$ was: $\mathrm{NaCl} \mathrm{116;} \mathrm{KCl} \mathrm{3;} \mathrm{MgSO}_{4} 1 ; \mathrm{KH}_{2} \mathrm{PO}_{4} 1.2$; NaHCO3 25; D-glucose 11; pH 7.4 saturated with $\mathrm{O}_{2} / \mathrm{CO}_{2}(95 / 5 \% \mathrm{v}: \mathrm{v})$. The brains were sliced into coronal sections $(250 \mu \mathrm{m}$ thick) using a vibratome (Leica). Coronal sections of the PFC were collected and kept in ice-cold, oxygenated $\mathrm{KH}$ buffer until used for testing. Sections from 4 animals/experiment were equilibrated at $37^{\circ} \mathrm{C}$ in $\mathrm{KH}$ buffer in the presence of $1.8 \mathrm{mM} \mathrm{CaCl}_{2}, 10 \mu \mathrm{M}$ pargyline, a MAO inhibitor, and $400 \mu \mathrm{M}$ ascorbic acid (efflux buffer) for $30 \mathrm{~min}$. After $30 \mathrm{~min}$, the slices were transferred to chambers containing efflux buffer $+\mathrm{drug}$ treatment (40 mM KCl+/- $10 \mu \mathrm{M}$ desipramine, $10 \mu \mathrm{M}$ GBR 12909, $10 \mu \mathrm{M}$ Fluoxetine) for $20 \mathrm{~min}$ at $37^{\circ} \mathrm{C}$. Following incubation with efflux buffer alone or efflux buffer + drug treatment, $0.1 \mathrm{M}$ perchloric acid was added to the supernatants collected from the samples. The supernatants were centrifuged for $5 \mathrm{~min}$ at $5000 \mathrm{~g}$. For amphetamine-induced monoamine release, data were normalized to $\mathrm{KCl}$-induced release for each genotype, respectively, to account for homeostatic changes in release due global deletion of transporters.

Monoamine levels were measured using an HTEC (Amuza Inc, San Diego, CA) HPLC system with an electrochemical detector. Monoamine release was calculated as the amount of catecholamines in the eluate normalized to total protein levels in the tissue samples and normalized to the $\mathrm{KCl}$-induced control samples. Data from at least 3 independent experiments (each experiment with tissue from $n=4$ mice) were pooled together.

PFC infusions. DAT-KO mice underwent surgery to implant bilateral cannula (Plastics One, 33-gauge, $1 \mathrm{~mm}$ ) into the PFC using stereotaxic coordinates from a mouse brain atlas (AP: + 2.4 mm, ML: $0.5 \mathrm{~mm}$, DV: $1.0 \mathrm{~mm}$ from bregma). Following at least 1-2 weeks of recovery, the mice were placed in an open-field testing chamber and baseline locomotor activity was assessed for $30 \mathrm{~min}$. Locomotor activity was paused while the mice received a bilateral infusion $(0.5 \mu \mathrm{l} / \mathrm{side})$ of either desipramine, fluoxetine, nepicastat (all $4 \mu \mathrm{g} / 0.5 \mu \mathrm{l})$, amphetamine $(100 \mu \mathrm{M} / 0.5 \mu \mathrm{l})$ or vehicle (aCSF or aCSF with $10 \%$ cyclodextrin, $1 \%$ DMSO for nepicastat) over a $2 \mathrm{~min}$ period. Locomotor activity recording was resumed for an additional $120 \mathrm{~min}$. Mice were injected with either vehicle or drug and after a 72-h drug washout, were counterbalanced and the injection groups were reversed.

Monoamine tissue level-HPLC analysis. WT, DAT-KO and NET-KO mice were sacrificed and brains were placed in a mouse brain matrix. The mouse brain matrix was used to take $1 \mathrm{~mm}$ coronal sections and punches of the PFC, and dorsal striatum (method described by Salvatore et al., 2012). The punches of each of the brain regions of interest were place on dry ice and stored at $-80^{\circ} \mathrm{C}$ until processed. For processing, tissue samples were placed in ice-cold $0.1 \mathrm{M} \mathrm{HClO} 4$ solution and sonicated at $30 \%$ of full power. The volume of $0.1 \mathrm{M}$ $\mathrm{HClO} 4$ solution was 20 times the weight of PFC and 40 times the weight of dorsal striatum tissue samples. The samples were subsequently centrifuged at $16,000 \mathrm{~g}$ for $15 \mathrm{~min}$ at $4{ }^{\circ} \mathrm{C}$ and the supernatants were placed in a separate tube from the protein precipitates. The supernatants were filtered and the filtrates were placed in HPLC tubes. Monoamine levels were determined by HPLC analysis with electrochemical detection (HTEC, Amuza Inc). 
Statistical analyses. All statistical analyses were performed using Graphpad prism 9.0. All group sizes for behavioral analyses are based on our previously published studies, as well as on power analyses suggesting that they will yield power to detect significant $($ alpha $=0.05)$ effects of 0.8 and above. Data were analyzed by unpaired t-test, One-way ANOVA, or Two-way ANOVA test for comparison between genotypes and/or injection pairs, as mentioned in figure legends. Individual genotypes, or injection pairs were compared using a post hoc Tukey's test. Data are presented as mean \pm SEM. $p<0.05$ is considered as significant.

\section{Data availability}

The datasets generated during and/or analyzed during the current study are stored on a University of Florida One Drive account and available from the corresponding author on reasonable request.

Received: 18 October 2021; Accepted: 7 February 2022

Published online: 24 February 2022

\section{References}

1. Gainetdinov, R. R. et al. Role of serotonin in the paradoxical calming effect of psychostimulants on hyperactivity. Science (New York, N.Y.) 283, 397-401 (1999).

2. Giros, B., Jaber, M., Jones, S. R., Wightman, R. M. \& Caron, M. G. Hyperlocomotion and indifference to cocaine and amphetamine in mice lacking the dopamine transporter. Nature 379, 606-612 (1996).

3. Bymaster, F. P. et al. Fluoxetine, but not other selective serotonin uptake inhibitors, increases norepinephrine and dopamine extracellular levels in prefrontal cortex. Psychopharmacology 160, 353-361. https://doi.org/10.1007/s00213-001-0986-x (2002).

4. Tanda, G., Carboni, E., Frau, R. \& Di Chiara, G. Increase of extracellular dopamine in the prefrontal cortex: A trait of drugs with antidepressant potential?. Psychopharmacology 115, 285-288. https://doi.org/10.1007/BF02244785 (1994).

5. Xu, F. et al. Mice lacking the norepinephrine transporter are supersensitive to psychostimulants. Nat. Neurosci. 3, 465-471. https:// doi.org/10.1038/74839(2000).

6. Moron, J. A., Brockington, A., Wise, R. A., Rocha, B. A. \& Hope, B. T. Dopamine uptake through the norepinephrine transporter in brain regions with low levels of the dopamine transporter: Evidence from knock-out mouse lines. J. Neurosci. 22, 389-395 (2002).

7. Ventura, R. et al. Dopamine in the medial prefrontal cortex controls genotype-dependent effects of amphetamine on mesoaccumbens dopamine release and locomotion. Neuropsychopharmacology 29, 72-80. https://doi.org/10.1038/sj.npp.1300300 (2004).

8. Ventura, R., Alcaro, A., Mandolesi, L. \& Puglisi-Allegra, S. In vivo evidence that genetic background controls impulse-dependent dopamine release induced by amphetamine in the nucleus accumbens. J. Neurochem. 89, 494-502. https://doi.org/10.1111/j.14714159.2004.02342.x (2004).

9. Sokolowski, J. D. \& Salamone, J. D. Effects of dopamine depletions in the medial prefrontal cortex on DRL performance and motor activity in the rat. Brain Res. 642, 20-28. https://doi.org/10.1016/0006-8993(94)90901-6 (1994).

10. Pycock, C. J., Kerwin, R. W. \& Carter, C. J. Effect of lesion of cortical dopamine terminals on subcortical dopamine receptors in rats. Nature 286, 74-76 (1980).

11. Berridge, C. W. et al. Methylphenidate preferentially increases catecholamine neurotransmission within the prefrontal cortex at low doses that enhance cognitive function. Biol. Psychiatry 60, 1111-1120. https://doi.org/10.1016/j.biopsych.2006.04.022 (2006).

12. Arnsten, A. F. \& Dudley, A. G. Methylphenidate improves prefrontal cortical cognitive function through alpha 2 adrenoceptor and dopamine D1 receptor actions: Relevance to therapeutic effects in attention deficit hyperactivity disorder. Behav. Brain Funct. 1, 2. https://doi.org/10.1186/1744-9081-1-2 (2005).

13. Pino, J. A., Awadallah, N., Norris, A. M. \& Torres, G. E. A plate-based assay for the measurement of endogenous monoamine release in acute brain slices. J. Vis. Exp. https://doi.org/10.3791/62127 (2021).

14. Johnson, L. A., Guptaroy, B., Lund, D., Shamban, S. \& Gnegy, M. E. Regulation of amphetamine-stimulated dopamine efflux by protein kinase C beta. J. Biol. Chem. 280, 10914-10919. https://doi.org/10.1074/jbc.M413887200 (2005).

15. Ciliax, B. J. et al. The dopamine transporter: Immunochemical characterization and localization in brain. J. Neurosci. 15, 1714-1723 (1995).

16. Sesack, S. R., Hawrylak, V. A., Guido, M. A. \& Levey, A. I. Cellular and subcellular localization of the dopamine transporter in rat cortex. Adv. Pharmacol. 42, 171-174 (1998).

17. Manvich, D. F., DePoy, L. M. \& Weinshenker, D. Dopamine beta-hydroxylase inhibitors enhance the discriminative stimulus effects of cocaine in rats. J. Pharmacol. Exp. Ther. 347, 564-573. https://doi.org/10.1124/jpet.113.207746 (2013).

18. Schroeder, J. P., Epps, S. A., Grice, T. W. \& Weinshenker, D. The selective dopamine beta-hydroxylase inhibitor nepicastat attenuates multiple aspects of cocaine-seeking behavior. Neuropsychopharmacology 38, 1032-1038. https://doi.org/10.1038/npp.2012. 267 (2013).

19. Devoto, P., Flore, G., Saba, P., Frau, R. \& Gessa, G. L. Selective inhibition of dopamine-beta-hydroxylase enhances dopamine release from noradrenergic terminals in the medial prefrontal cortex. Brain Behav. 5, e00393. https://doi.org/10.1002/brb3.393 (2015).

20. Yamashita, M. et al. Norepinephrine transporter blockade can normalize the prepulse inhibition deficits found in dopamine transporter knockout mice. Neuropsychopharmacology 31, 2132-2139. https://doi.org/10.1038/sj.npp.1301009 (2006).

21. Sora, I. et al. Molecular mechanisms of cocaine reward: combined dopamine and serotonin transporter knockouts eliminate cocaine place preference. Proc. Natl. Acad. Sci. U.S.A. 98, 5300-5305. https://doi.org/10.1073/pnas.091039298 (2001).

22. Watabe-Uchida, M., Zhu, L., Ogawa, S. K., Vamanrao, A. \& Uchida, N. Whole-brain mapping of direct inputs to midbrain dopamine neurons. Neuron 74, 858-873. https://doi.org/10.1016/j.neuron.2012.03.017 (2012).

23. Beier, K. T. et al. Circuit architecture of VTA dopamine neurons revealed by systematic input-output mapping. Cell 162, 622-634. https://doi.org/10.1016/j.cell.2015.07.015 (2015).

24. Schwarz, L. A. et al. Viral-genetic tracing of the input-output organization of a central noradrenaline circuit. Nature 524, 88-92. https://doi.org/10.1038/nature14600 (2015).

25. Sotnikova, T. D. et al. Dopamine-independent locomotor actions of amphetamines in a novel acute mouse model of Parkinson disease. PLoS Biol 3, e271. https://doi.org/10.1371/journal.pbio.0030271 (2005).

26. Green, S. M., Nathani, S., Zimmerman, J., Fireman, D. \& Urs, N. M. Retrograde labeling illuminates distinct topographical organization of D1 and D2 receptor-positive neurons in the prefrontal cortex of mice. eNeuro https://doi.org/10.1523/ENEURO.0194-20. 2020 (2020)

27. Urs, N. M., Daigle, T. L. \& Caron, M. G. A dopamine D1 receptor-dependent beta-arrestin signaling complex potentially regulates morphine-induced psychomotor activation but not reward in mice. Neuropsychopharmacology 36, 551-558. https://doi.org/10. 1038/Npp.2010.186 (2011). 


\section{Acknowledgements}

This work was supported by a NARSAD/BBRF (Grant No. 27765) Young Investigator grant (to NU). We would like to thank Dr. Marc Caron for providing us with catecholamine transporter knockout mice.

\section{Author contributions}

S.S.H.-conceptualized experiments, performed experiments, analyzed data, wrote manuscript. S.M.G.-performed experiments, analyzed data. M.K.-performed experiments, analyzed data. N.M.U.-conceptualized experiments, performed experiments, analyzed data, wrote manuscript.

\section{Competing interests}

The authors declare no competing interests.

\section{Additional information}

Supplementary Information The online version contains supplementary material available at https:/doi.org/ 10.1038/s41598-022-07029-2.

Correspondence and requests for materials should be addressed to N.M.U.

Reprints and permissions information is available at www.nature.com/reprints.

Publisher's note Springer Nature remains neutral with regard to jurisdictional claims in published maps and institutional affiliations.

(c) (i) Open Access This article is licensed under a Creative Commons Attribution 4.0 International License, which permits use, sharing, adaptation, distribution and reproduction in any medium or format, as long as you give appropriate credit to the original author(s) and the source, provide a link to the Creative Commons licence, and indicate if changes were made. The images or other third party material in this article are included in the article's Creative Commons licence, unless indicated otherwise in a credit line to the material. If material is not included in the article's Creative Commons licence and your intended use is not permitted by statutory regulation or exceeds the permitted use, you will need to obtain permission directly from the copyright holder. To view a copy of this licence, visit http://creativecommons.org/licenses/by/4.0/.

(C) The Author(s) 2022 